\title{
A New $(3,6)$-Connected Heterometallic Coordination Polymer: Therapeutic and Protective Effect on Ischemic Cerebral Infarction
}

\author{
Jia Ma $\mathbb{D}^{1},{ }^{1}$ Jianer Wang $\mathbb{D},{ }^{2}$ Yuping He $\mathbb{D}^{3},{ }^{3}$ Yiwei Huang $\left(\mathbb{D},{ }^{3}\right.$ and Yejun Chen $\mathbb{D}^{3}$ \\ ${ }^{1}$ Department of Neurology, Ningbo Yinzhou No. 2 Hospital, Ningbo, Zhejiang, China \\ ${ }^{2}$ Department of Neurology, Yuhang District Second People's Hospital, Hangzhou, Zhejiang, China \\ ${ }^{3}$ Department of Neurology, Zhuji Affiliated Hospital of Shaoxing University, Zhuji, Zhejiang, China
}

Correspondence should be addressed to Yejun Chen; chenyejun2021@yeah.net

Received 29 July 2021; Revised 20 September 2021; Accepted 11 October 2021; Published 31 October 2021

Academic Editor: Marcelino Maneiro

Copyright (C) 2021 Jia Ma et al. This is an open access article distributed under the Creative Commons Attribution License, which permits unrestricted use, distribution, and reproduction in any medium, provided the original work is properly cited.

\begin{abstract}
Solvothermal reaction of 4,4',4'-nitrilotribenzoic acid $\left(\mathrm{H}_{3} \mathrm{TCA}\right)$ with $\mathrm{Ca}\left(\mathrm{NO}_{3}\right)_{2} \cdot 4 \mathrm{H}_{2} \mathrm{O}$ and $\mathrm{Cd}\left(\mathrm{NO}_{3}\right)_{2} \cdot 4 \mathrm{H}_{2} \mathrm{O}$ successfully afforded a heterometallic compound, that is, $\left[\mathrm{Cd}_{2} \mathrm{Ca}(\mathrm{TCA})_{2}(\mathrm{DMA})_{2}\left(\mathrm{H}_{2} \mathrm{O}\right)_{3}\right]_{\mathrm{n}} \cdot 2 \mathrm{n}(\mathrm{DMA})\left(\mathbf{1}, \mathrm{DMA}=\mathrm{N}, \mathrm{N}^{\prime}\right.$-dimethylacetamide). The structure of 1 was further characterized through EA, diffraction of single crystal X-ray, and thermogravimetric analysis (TGA) together with powder X-ray diffraction (PXRD). Moreover, complex 1's luminescent performance in solid state was also discussed at environmental temperature. The applications on the ischemic cerebral infarction therapy were evaluated, and the specific mechanism was investigated at the same time. Firstly, the hypersensitivity C-reactive protein (hs-CRP) content in human brain microvascular endothelial cell (HBMEC) was measured with real-time reverse transcription-polymerase chain reaction (RT-PCR). Then, interleukin-18 and interleukin-1 $\beta$ content released through the HBMEC was detected with enzyme-linked immunosorbent assay (ELISA).
\end{abstract}

\section{Introduction}

Ischemic cerebral infarction refers to the degeneration, necrosis, or transient loss of function of the local brain tissue including nerve cells, glial cells, and connecting fibers due to blood supply disorders [1]. It accounts for about $80 \%$ of vascular diseases and are common clinical diseases and frequently-occurring diseases, with high mortality and disability rates [2]. Recently, the immune inflammatory response reported playing an important role in the development of the ischemic cerebral infarction. Thus, the new candidates targeting the inflammatory response were needed to be studied [3].

In the last several decades, a great deal of the coordination polymers (CPs) having fascinating topological skeletons have been triumphantly produced by the polydentate organic ligands and metal ions or polynuclear metal clusters, and these crystalline CPs also show promising application properties, such as luminescence sensing, molecular recognition, gas storage/separation, and heterogeneous catalysis that have attracted tremendous interest for the development of new inorganic-organic hybrid materials [4-8]. From these reports, it can be found that the structure and properties of $\mathrm{CPs}$ are intimately related with the selected organic ligands. To construct the desired CPs, the key factor is the intelligent selection of suitable organic ligands with appropriate shape, flexibility, symmetry, and coordination functional groups [9-11]. As a representative multidentate ligand, multicarboxylate ligands show outstanding coordination capacities and versatile coordination modes for the formation of CPs, and interestingly, the carboxylic acid groups can connect metal ions into a variety of chains with rod-shape or polynuclear clusters that can be served as second building subunits to direct the construction of CPs $[6,12-14]$. In the reports, Yao and his coworkers found that the combination of alkaline Earth metal ions and $\mathrm{Zn}(\mathrm{II})$ or $\mathrm{Cd}(\mathrm{II})$ ions with aromatic carboxylate ligands is easy to form heterometallic CPs with different seconding building subunits $[15,16]$. As a $C_{3}$ symmetric ligand, $4,4^{\prime}, 4^{\prime \prime}$-nitrilotribenzoic acid $\left(\mathrm{H}_{3} \mathrm{TCA}\right)$ has three carboxylate groups and a large triphenylamine chromophore, which makes it a good organic building block for the construction of luminescent 
CPs [17-19]. As yet, in the TCA-based heterometallic CPs, as far as we know, there are still few reports. Considering this, in this work, we employed $\mathrm{H}_{3}$ TCA to self-assemble with the $\mathrm{Ca}(\mathrm{II})$ and $\mathrm{Cd}$ (II) mixed metal ions under solvothermal conditions. Triumphantly, we obtained a fresh heterometallic compound formulated as $\left[\mathrm{Cd}_{2} \mathrm{Ca}(\mathrm{TCA})_{2}(\mathrm{DMA})_{2}\left(\mathrm{H}_{2} \mathrm{O}\right)_{3}\right]_{\mathrm{n}} \cdot 2 \mathrm{n}(\mathrm{DMA})$ (1). Also, the thermostability and luminescent property of $\mathbf{1}$ were investigated. Furthermore, the biological activity of the new compound was evaluated, and the related mechanism was explored as well. The results of the real-time PCR indicated that the expression level of the hs-CRP expression in HBMEC was significantly reduced by the new compound. Besides, the IL- $1 \beta$ and IL-18 content released by HBMEC was also reduced by the new compound, which was measured by the ELISA assay.

\section{Experimental}

2.1. Materials and Instrumentation. The used chemical reagents were commercially available from Shanghai Aladdin Bio-Chem Technology Co., Ltd. PXRD was analyzed through applying the PANalytical X'Pert at $0.05^{\circ}$ step size using the $\mathrm{Cu} / \mathrm{K} \alpha$ radiation (where $\lambda$ is $1.54056 \AA$ ). The hydrogen, nitrogen, as well as carbon elements were analyzed through employing Vario EL III. With the temperature of $30-800^{\circ} \mathrm{C}$, TGA was accomplished with the NETSCHZ STA-449C at $10^{\circ} \mathrm{C}$ per min heating rate under a flow of nitrogen. Edinburg FLS920 TCSPC was exploited to collect luminescent spectra at ambient temperature.

\subsection{Synthesis of Compound $\left[\mathrm{Cd}_{2} \mathrm{Ca}(T C A)_{2}(\mathrm{DMA})_{2}\left(\mathrm{H}_{2}\right.\right.$} $\left.\mathrm{O}_{3}\right]_{n} \cdot 2 n(D M A)$ (1). The mixture synthesized from $0.100 \mathrm{mmol} \mathrm{Cd}\left(\mathrm{NO}_{3}\right)_{2} \cdot 4 \mathrm{H}_{2} \mathrm{O}, 0.05 \mathrm{mmol} \mathrm{Ca}\left(\mathrm{NO}_{3}\right)_{2} \cdot 4 \mathrm{H}_{2} \mathrm{O}$, $0.1 \mathrm{mmol} \mathrm{H}_{3}$ TCA, $3 \mathrm{~mL} \mathrm{DMA}$, and $1.0 \mathrm{~mL} \mathrm{H}_{2} \mathrm{O}$ was sealed into a small glass vial $(20 \mathrm{~mL})$, and this vial was heated for one day at $110^{\circ} \mathrm{C}$ temperature. After the mixture naturally cooled to environmental temperature, the colorless massive crystals were produced with 46 percent yield in accordance with $\mathrm{H}_{3}$ TCA. Elemental analysis calcd. for the $\mathrm{C}_{58} \mathrm{H}_{66} \mathrm{CaCd}_{2}$ $\mathrm{N}_{6} \mathrm{O}_{19}$ (1416.06): N, 5.93, C, 49.15, and H, 4.66\%. Found: $\mathrm{N}, 5.96, \mathrm{C}, 49.13$ and $\mathrm{H}, 4.62 \%$. IR (KBr pallet, $\left.\mathrm{cm}^{-1}\right): 3423$ (m), 3063 (m), 2934 (m), 2783 (m), 1593 (s), 1563 (s), 1489 (s), 1451 (s), $1380(\mathrm{~m}), 1364$ (m), 1338 (s), 1312 (s), 1233 (s), 1162 (m), 1150 (m), 1108 (s), 1026 (m), 1005 (w), 925 (s), 836 (m), $776(\mathrm{~s}), 756(\mathrm{~s}), 710(\mathrm{~m}), 689(\mathrm{~s}), 618(\mathrm{w}), 580(\mathrm{w}), 535(\mathrm{~s})$.

2.3. X-Ray Crystallography. For the compound, its data of single crystal were recorded with the diffractometer of mercury CCD controlled through computer, which was equipped with graphite monochromated Mo-K $\alpha$ radiation (in which $\lambda$ is $0.71073 \AA$ ) under ambient temperature. ShelXS with direct methods and ShelXL with least squares minimization were, respectively, employed to solve and refine the architecture [20]. The disordered molecules of DMA were squeezed out through exploiting PLATON [21]. The data of crystallography for the complex are illustrated in Table 1.
TABLE 1: The compound's crystal data.

\begin{tabular}{lc}
\hline Formula & $\mathrm{C}_{58} \mathrm{H}_{66} \mathrm{CaCd}_{2} \mathrm{~N}_{6} \mathrm{O}_{19}$ \\
Fw & 1416.06 \\
Crystal system & Orthorhombic \\
Space group & $P b c n$ \\
$a(\AA)$ & $24.2583(9)$ \\
$b(\AA)$ & $11.7412(8)$ \\
$c(\AA)$ & $22.5566(12)$ \\
$\alpha\left(\left(^{\circ}\right)\right.$ & 90 \\
$\beta\left(^{\circ}\right)$ & 90 \\
$\gamma\left({ }^{\circ}\right)$ & 90 \\
Volume $\left(\AA^{3}\right)$ & $6424.6(6)$ \\
$Z$ & 4 \\
Density (calculated) & 1.284 \\
Abs. coeff. (mm $\left.{ }^{-1}\right)$ & 0.802 \\
Total reflections & 67535 \\
Unique reflections & 12019 \\
Goodness of fit on $F^{2}$ & 0.933 \\
Final $R$ indices $\left(I>2\right.$ sigma $\left.\left(I^{2}\right)\right)$ & $R=0.0881, w R_{2}=0.1901$ \\
$R$ (all data) & $R=0.2226, w R_{2}=0.2509$ \\
CCDC & 2096366 \\
\hline
\end{tabular}

2.4. Real-Time PCR. After the synthesis of the new compound, its therapeutic activity on the ischemic cerebral infarction was determined. As we all know, there was a remarkably increased hs-CRP level during the procession of cerebral infarction, which was also regarded as the indicator of acute phase inflammation of cerebral infarction. Thus, in this present research, the real-time PCR was conducted, and the hs-CRP expression level in HBMEC after compound treatment was measured following the instructions. In short, the HBMEC in the logical growth phase was harvested and seeded into a 6-well plate at a concentration of $10^{5}$ cells per well. After $12 \mathrm{~h}$ of incubation at $37^{\circ} \mathrm{C}, 5 \% \mathrm{CO}_{2}$ condition, the cells were treated with hypoxia culture, followed by the compound treatment at the concentration of 1,2 , and $5 \mu \mathrm{g} /$ ml. Next, the cells were collected, and the total RNA was extracted with RNA isolation kit, with the ligand and metal ion used as the negative control. The spectrophotometer was used to measure the concentration of the total RNA, which was then reverse-transcripted into cDNAs using a highcapacity cDNA reverse transcription kit. Finally, the PCR detection was carried out with Step One Plus Real-time PCR systems. The hs-CRP relative expression in the HBMEC was evaluated with GADPH used as an inner reference.

2.5. ELISA Assay. As IL- $1 \beta$ and IL-18 has been widely regarded as the important indicator of the cerebral infarction, the ELISA assay was next conducted, and the IL- $1 \beta$ and IL-18 content released by HBMEC was measured in this study. All preformation was finished according to the manufacturer's instructions with some changes. In brief, the HBMEC in the logical growth phase was harvested and seeded into a 6 -well plate $\left(10^{5}\right.$ cells/well). After $12 \mathrm{~h}$ of incubation in an incubator at $37^{\circ} \mathrm{C}, 5 \% \mathrm{CO}_{2}$ condition, the cells were treated with hypoxia culture as well the treatment of compound at $1 \mu \mathrm{g} / \mathrm{ml}, 2 \mu \mathrm{g} / \mathrm{ml}$, and $5 \mu \mathrm{g} / \mathrm{ml}$ concentration, with the ligand and metal ion used as the negative control. After treated with the compound, the culture supernatant 
was harvested, and the IL-18 and IL- $1 \beta$ content was measured with ELISA assay. This research was performed for 3 times, and the results were presented as mean \pm SD.

\section{Results and Discussion}

3.1. Crystal Structure of Compound 1. Compound $\mathbf{1}$ was prepared via reaction of $\mathrm{Cd}\left(\mathrm{NO}_{3}\right)_{2} \cdot 4 \mathrm{H}_{2} \mathrm{O}, \mathrm{Ca}\left(\mathrm{NO}_{3}\right)_{2} \cdot 4 \mathrm{H}_{2} \mathrm{O}$ and $\mathrm{H}_{3}$ TCA in a mixed solvent of DMA and $\mathrm{H}_{2} \mathrm{O}$ at $110^{\circ} \mathrm{C}$ for one day. The $\mathrm{H}_{3}$ TCA ligand could not be dissolved in water nor EtOH but could be dissolved in DMA by stirring, so we used $\mathrm{H}_{3}$ TCA as the main solvent in this reaction. The compound's architecture reveals a three-dimensional skeleton according to trinuclear subunits based on the $\left[\mathrm{Cd}_{2} \mathrm{Ca}(\mathrm{COO})_{4}\right]$ cluster, which was crystallized in the space group $\mathrm{Pbcn}$ of the orthorhombic system. The compound's fundamental unit is constructed from a Cd(II) ion, $0.5 \mathrm{Ca}$ (II) ion, a ligand of $\mathrm{TCA}^{3-}$, a coordinated molecule of DMA, one and a half coordinated molecules of water, together with a molecule of DMA. As reflected in the Figure 1(a), the Cd1 ion is six-coordinated through 5 carboxylic acid $\mathrm{O}$ atoms coming from 3 ligands of $\mathrm{TCA}^{3-}$ and an atom of a terminal molecule of DMA, displaying a highly distorted structure of octahedron, and the $\mathrm{Cal}$ ion is 7-coordinated via 4 carboxylic acid $\mathrm{O}$ atoms derived from 4 diverse ligands of $\mathrm{TCA}^{3-}$ and 3 terminal ligands of water, displaying a pentagonal bipyramidal structure. The distance of $\mathrm{Cd}-\mathrm{O}$ is between 2.226 (8) and 2.449 (5) $\AA$, and the separation of CaO varying from 2.278 (4) to $2.584(10) \AA$, respectively, is in a normal range, which is in accordance with the lengths of reported compounds [12]. One $\mathrm{Ca}$ (II) ion as well as two symmetry-related $\mathrm{Cd}(\mathrm{II})$ ions are connected through 4 carboxylic acid groups to create a trinuclear subunit based on the $\left[\mathrm{Cd}_{2} \mathrm{Ca}(\mathrm{COO})_{4}\right]$ cluster, and the distance of $\mathrm{Cd}$. . Ca is $3.90 \AA$ (Figure 1(b)). In the end, these trinuclear subunits based on the cluster are linked together via the ligands of $\mathrm{TCA}^{3-}$, generating the compound's three-dimensional skeleton (Figure 1(c)). In this three-dimensional skeleton, each ligand of $\mathrm{TCA}^{3-}$ connects 3 diverse trinuclear clusters $\left[\mathrm{Cd}_{2} \mathrm{Ca}(\mathrm{COO})_{4}\right]$, and each of the trinuclear cluster $\left[\mathrm{Cd}_{2} \mathrm{Ca}(\mathrm{COO})_{4}\right]$ is supported through 6 distinct ligands of $\mathrm{TCA}^{3-}$, By viewing $\mathrm{TCA}^{3-}$ ligands and trinuclear $\left[\mathrm{Cd}_{2} \mathrm{Ca}(\mathrm{COO})_{4}\right]$ clusters as three- and six-linked nodes, respectively (Figures $1(\mathrm{~d})$ and $1(\mathrm{e})$ ), the compound's entire framework can be reduced topologically as a $(3,6)$-linked apo net, with $\left\{4.6^{2}\right\}_{2}\left\{4^{2} \cdot 6^{9} \cdot 8^{4}\right\}$ point symbol (Figure $1(\mathrm{f})$ ).

\subsection{Powder X-Ray Diffraction Pattern (PXRD) and Ther-} mogravimetric Analysis (TGA). The study of PXRD was employed to demonstrate the bulk samples' purity. As displayed in Figure 2(a), there exists an excellent match between the pattern of experiment and simulation, which reflects that the as-created samples are in pure phase. Considering the following bioactivity tests, it is necessary to study the framework stability of complex $\mathbf{1}$ in the dispersing solvent DMSO and the simulated in vivo condition phosphate buffered saline (PBS). As complex 1 could not be dissolved in organic solvents and water, we used its stock solution in the following bioactivity tests according to the methods proposed in $[22,23]$. With this in mind, about $100 \mathrm{mg}$ of the as-prepared crystalline samples of 1 was taken in a mortar. It was then being ground manually for $30 \mathrm{~min}$ by using an pestle. The produced fine powders were soaked in $20 \mathrm{~mL}$ PBS or DMSO and subjected to the ultrasonic treatments for 2 hours to obtain the well-dispersed solution. After standing for two days, the fine powders could be recovered via centrifugation, and their PXRD measurements show that the PXRD profiles of the treated samples show good matches with those of the as-prepared samples, reflecting their good stability in the above conditions.

TGA experiment for $\mathbf{1}$ was also carried out under nitrogen atmosphere. In the complex's curve of TGA, the first found weightlessness appearing in the temperature of $91-152^{\circ} \mathrm{C}$ was caused via the departure of the coordinated molecules of DMA and water, as well as the lattice DMA molecules (obsd: $28.50 \%$, calcd: $28.42 \%$ ), and the second found weightlessness appeared between 285 and $442^{\circ} \mathrm{C}$ that is on account of the organic ligand combustion, resulting in the generation of $\mathrm{CaO}$ and $\mathrm{CdO}$ as the ultimate residues of 22.12 percent (with $22.10 \%$ calculated value).

3.3. Luminescent Property of 1. Coordination polymers based on large conjugated organic ligands usually show interesting luminescent properties and can be served as hybrid materials in the fields of chemical sensors, light-emitting diodes (LEDs), and photochemistry $[24,25]$. As a result, the luminescent spectra of free ligand of $\mathrm{H}_{3}$ TCA and complex 1 in solid state were detected at environmental temperature. With $330 \mathrm{~nm}$ excitation, free ligand of $\mathrm{H}_{3}$ TCA shows intense luminescence with the maximum emission peak at $435 \mathrm{~nm}$, which is probably owing to the transition of $\pi^{*} \longrightarrow \pi$ of triphenylamine moiety (Figure 3). After complexation of $\mathrm{TCA}^{3-}$ ligand with $\mathrm{Ca}(\mathrm{II})$ and $\mathrm{Cd}(\mathrm{II})$ ions, a more intense emission peak for 1 can be found at $452 \mathrm{~nm}$ excitation (with $\lambda_{\text {ex }}$ of $350 \mathrm{~nm}$ ). Significantly, complex 1's emission spectrum is similar to the emission spectrum of free ligand of $\mathrm{H}_{3} \mathrm{TCA}$, and complex 1's maximum peak exhibits $17 \mathrm{~nm}$ red-shift in comparison with that of free ligand of $\mathrm{H}_{3}$ TCA. Because $\mathrm{Ca}(\mathrm{II})$ and $\mathrm{Cd}(\mathrm{II})$ ions are difficult to reduce or oxidize, the 1's emission is probably due to the charge transfer in the ligand that are perturbed by the metal-ligand coordination interactions and the deprotonated effect of the tricarboxylate ligands $[10,26,27]$.

3.4. Significantly Reduced hs-CRP Expression Levels in HBMEC after Compound Treatment. hs-CRP is a nonspecific acute phase reaction protein, which is widely regarded as the indicator of the ischemic cerebral infarction acute phase inflammation. During the procession of cerebral infarction, hs-CRP also exhibited an increased level. In this recent research, after the successful synthesis of the compound, the protective effect of the new compound against the ischemic cerebral infarction was evaluated by real-time PCR via measuring the hs-CRP expression levels in HBMEC. As the results shown in Figure 4, we can see that, in contrast to the control group, there was a remarkably enhanced hs- 


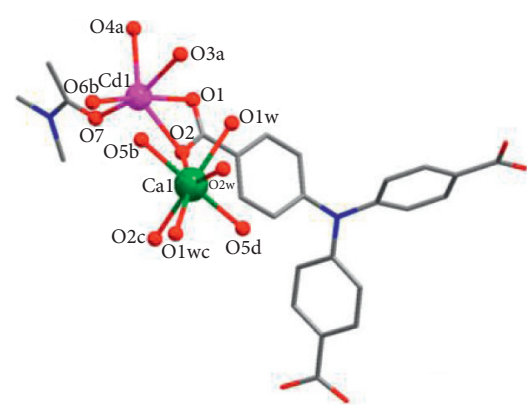

(a)

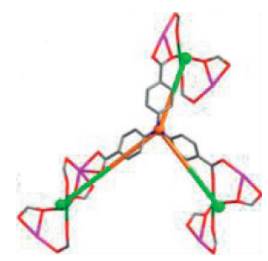

(d)

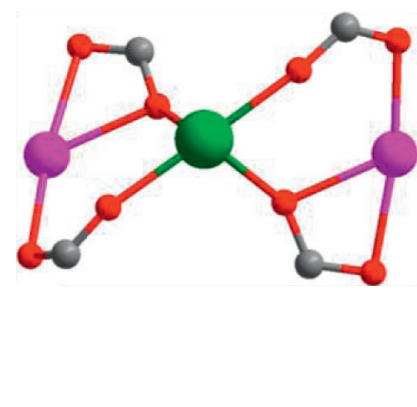

(b)

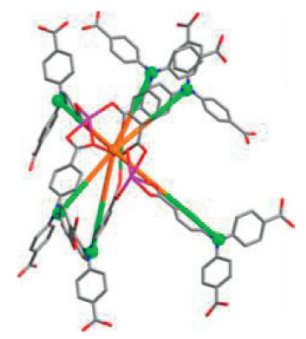

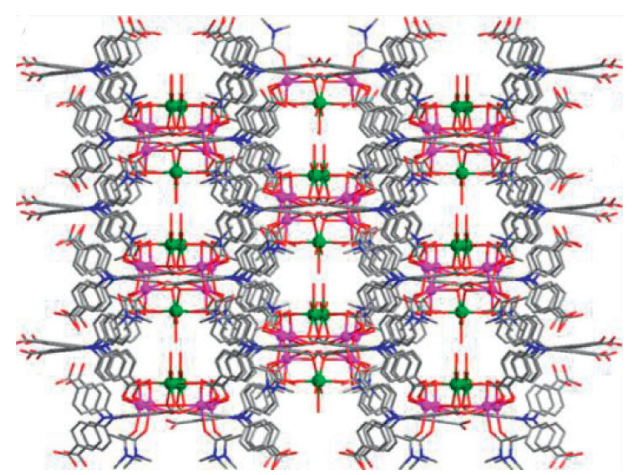

(c)

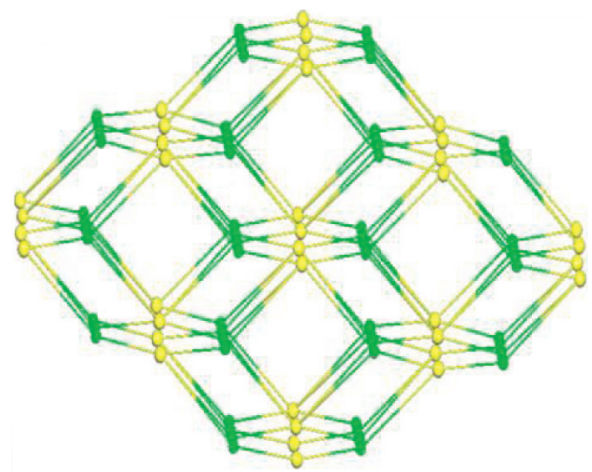

(f)

Figure 1: (a) The coordination surroundings of $\mathrm{Ca}(\mathrm{II})$ and $\mathrm{Cd}(\mathrm{II})$ ions in complex 1. (b) The heterometallic trinuclear cluster of $\left[\mathrm{Cd}{ }_{2} \mathrm{Ca}(\mathrm{COO})_{4}\right]$. (c) The compound's three-dimensional skeleton. (d) The defined three-linked node. (e) The defined six-linked node. (f) Complex 1's representation of $(3,6)$-linked apo topological net (green ball: $\left[\mathrm{Cd}_{2} \mathrm{Ca}(\mathrm{COO})_{4}\right]$ cluster; yellow ball: $\mathrm{TCA}^{3-}$ ligand).

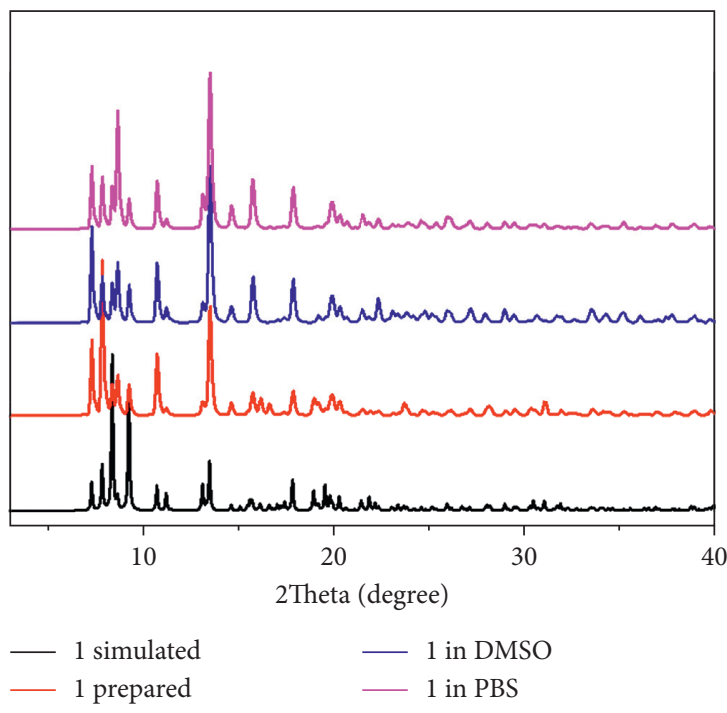

(a)

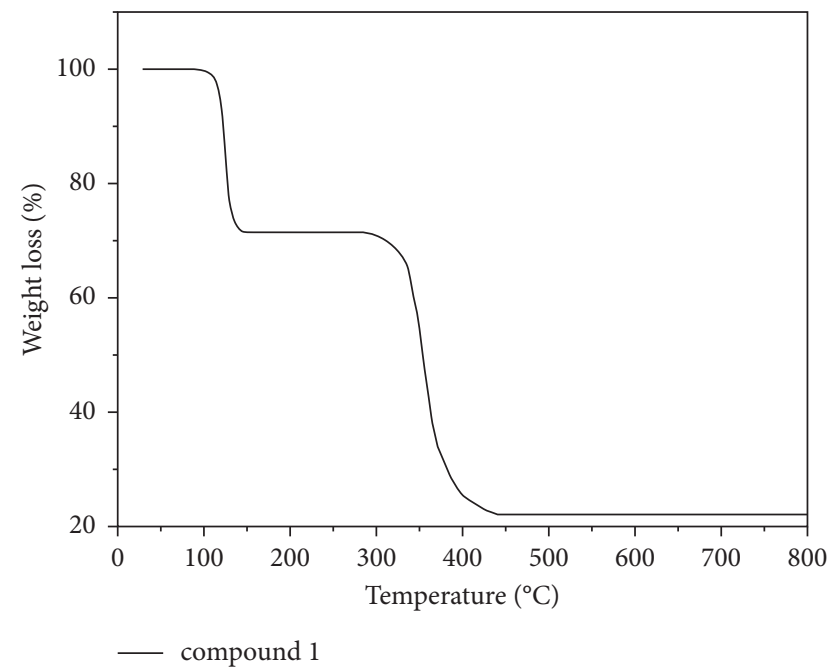

(b)

Figure 2: (a) The compound's manners of PXRD. (b) The 1's curve of TGA.

CRP level in HBMEC of the model group, with $p<0.005$. However, this abnormal increased level of the hs-CRP in HBMEC was obviously reduced under the treatment of a new compound. The inhibition of the new compound revealed a time-dependent correlation. While, the ligand and the metal ion showed almost no influence on the hs-CRP expression levels in HBMEC. This data indicated the compound exhibits outstanding protective effect in cerebral infarction treatment through reducing hs-CRP expression levels in HBMEC. 


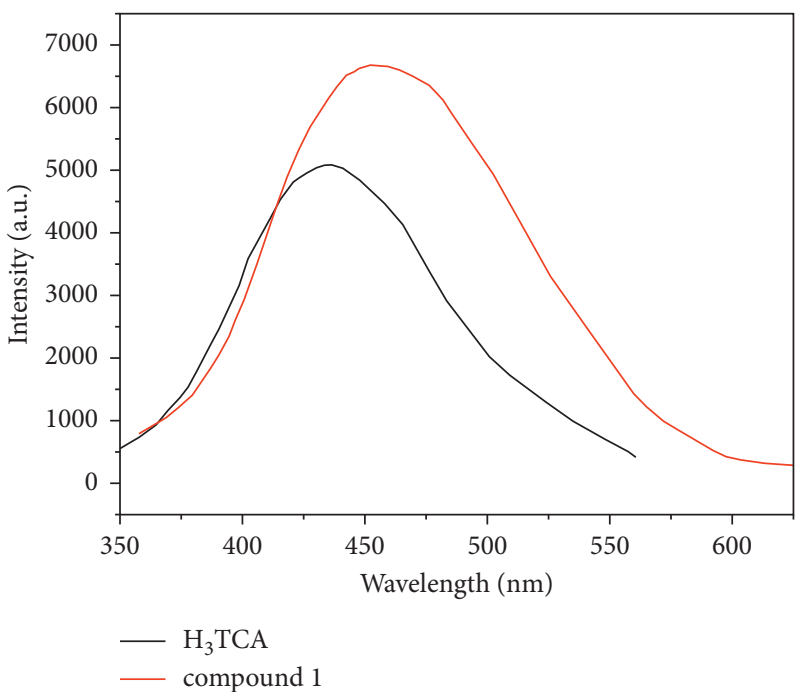

Figure 3: The luminescent emission spectra of free ligand of $\mathrm{H}_{3}$ TCA and complex $\mathbf{1}$ in solid state at ambient temperature.
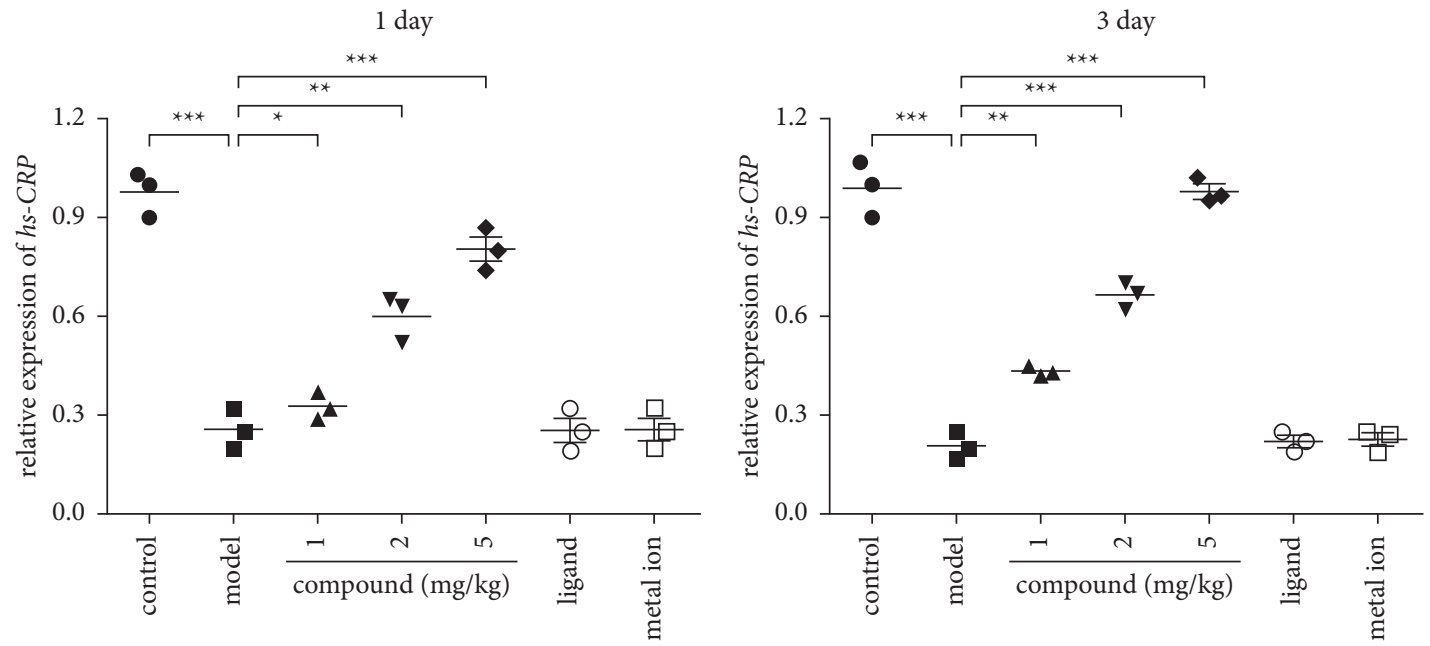

FIGURE 4: The compound could significantly reduce the hs-CRP expression levels in HBMEC.
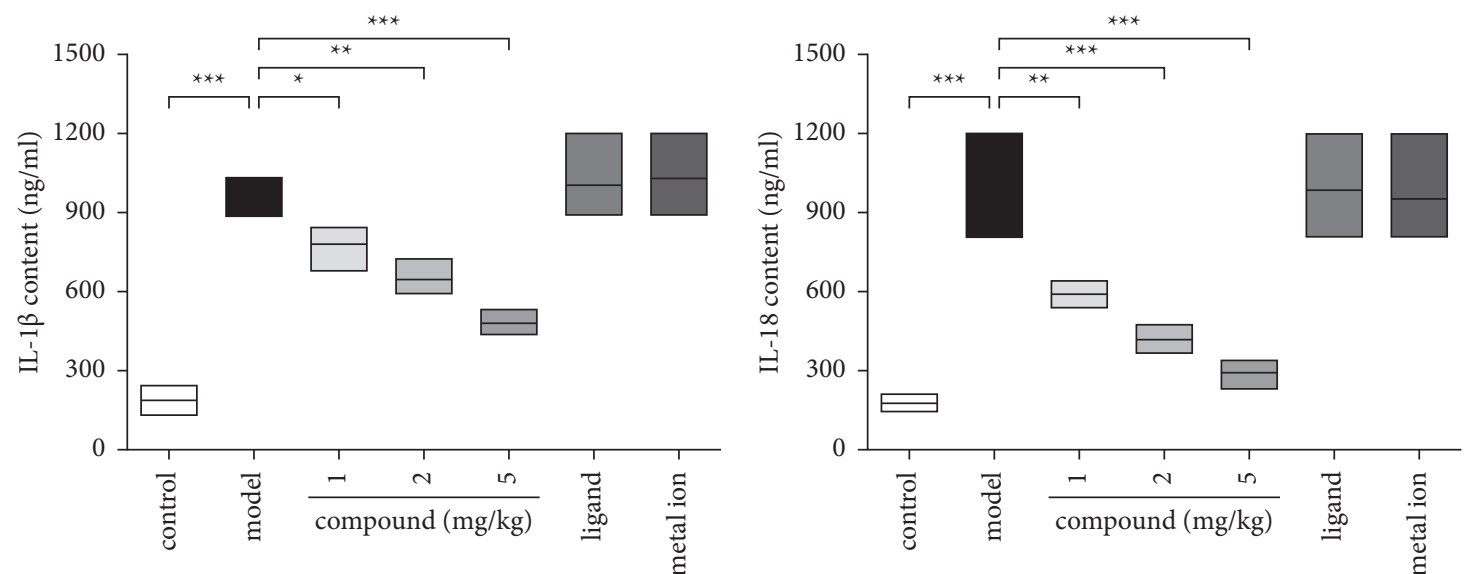

FIgURE 5: The compound obviously inhibited the releasing of IL-1 $\beta$ and IL-18 by HBMEC. The HBMEC cells were treated with hypoxia culture as well the compound treatment at the concentration of 1,2 , and $5 \mu \mathrm{g} / \mathrm{ml}$, with the ligand and metal ion used as the negative control. 
The HBMEC cells were treated with hypoxia culture as well, and the compound treatment at the concentration of 1 , 2 , and $5 \mu \mathrm{g} / \mathrm{ml}$, with the ligand and metal ion, is used as the negative control. Then, the real-time PCR was used to measure hs-CRP expression levels in HBMEC which obviously inhibited releasing of IL-18 and IL- $1 \beta$ by HBMEC after compound treatment.

In the above research, we have revealed that the compound has excellent inhibitory effect on the hs-CRP expression in HBMEC in a dose-dependent manner. In addition to this, the increased level of IL- $1 \beta$ and IL-18 has been widely regarded as the important indicator of the cerebral infarction. Thus, the IL- $1 \beta$ and IL- 18 content released by HBMEC was measured by ELISA assay. As the results shown in Figure 5, we can see that the level of IL-1 $\beta$ and IL-18 was significantly increased in the model group, compared with the control group. But, the levels of the inflammatory cytokines could be reversed under the treatment of the new compound in a dose-dependent manner. While, the ligand and the metal ion showed almost no influence on the IL-18 level and IL- $1 \beta$ level in HBMEC. This data revealed that the compound could release the IL-18 level and IL- $1 \beta$ level in HBMEC during cerebral infarction.

\section{Conclusion}

In conclusion, we synthesized a new heterometallic compound of $\left[\mathrm{Cd}_{2} \mathrm{Ca}(\mathrm{TCA})_{2}(\mathrm{DMA})_{2}\left(\mathrm{H}_{2} \mathrm{O}\right)_{3}\right]_{\mathrm{n}} \bullet 2 \mathrm{n}(\mathrm{DMA})$ (1) via the solvothermal self-assembly of $\mathrm{H}_{3} \mathrm{TCA}, \mathrm{Ca}\left(\mathrm{NO}_{3}\right)_{2} \cdot 4 \mathrm{H}_{2} \mathrm{O}$ and $\mathrm{Cd}\left(\mathrm{NO}_{3}\right)_{2} \cdot 4 \mathrm{H}_{2} \mathrm{O}$. Compound 1 exhibits a three-dimensional skeleton with heterometallic trinuclear clusters building subunits of $\left[\mathrm{Cd}_{2} \mathrm{Ca}(\mathrm{COO})_{4}\right]$ and reflected a $(3,6)$ linked apo topological net. Under the environmental temperature, 1 reveals strong luminescence centered at ligand. The results of the real-time PCR indicated that the expression level of the hs-CRP expression in HBMEC was significantly reduced by the new compound. Besides, the IL$1 \beta$ and IL- 18 content released by HBMEC was also reduced by the new compound, which was measured by the ELISA assay. In the end, we draw this conclusion. The new compound reveals outstanding application values against the ischemic cerebral infarction therapy by reducing the content of hypersensitivity C-reactive protein.

\section{Data Availability}

The data used to support the findings of this study are available from the corresponding author upon request.

\section{Conflicts of Interest}

The authors declare that there are no conflicts of interest regarding the publication of this paper.

\section{Authors' Contributions}

Jia Ma and Jianer Wang contributed equally to this work.

\section{Acknowledgments}

The research was supported by the Clinical Research Fund of Zhejiang Medical Association (2018ZYC-A111).

\section{References}

[1] Ó. Sveinsson, Ó. Kjartansson, Ó. Kjartansson, and E. M. Valdimarsson, "Heilablóðpurrð/-drep-greining og meðferð," Loeknablaðið, vol. 100, pp. 393-401, 2014.

[2] H. Takeda, T. Yamaguchi, H. Yano, and J. Tanaka, "Microglial metabolic disturbances and neuroinflammation in cerebral infarction," Journal of Pharmacological Sciences, vol. 145, no. 1, pp. 130-139, 2021.

[3] H. L. Huang, N. Wang, H. Zhou, and C. Y. Yu, "Study on influence of transient ischemic attack on subsequent cerebral infarction," European Review for Medical and Pharmacological Sciences, vol. 20, pp. 5164-5167, 2016.

[4] F. Yang, J. Wang, and P.-L. Zhang, "A Mn(II)-based coordination polymer: treatment activity on cerebral infarction by reducing inflammatory response via regulating hs-CRP expression," Main Group Chemistry, vol. 20, no. 2, pp. 165-173, 2021.

[5] D. Zhao, J. Song, X. Zhang et al., "A pillar-layered binuclear $3 \mathrm{D}$ cobalt(ii) coordination polymer as an electrocatalyst for overall water splitting and as a chemosensor for $\mathrm{Cr}(\mathrm{vi})$ anion detection," CrystEngComm, vol. 23, no. 36, pp. 6245-6252, 2021.

[6] F. Wang, F. Tian, Y. Deng et al., "Cluster-based multifunctional copper(II) organic framework as a photocatalyst in the degradation of organic dye and as an electrocatalyst for overall water splitting," Crystal Growth \& Design, vol. 21, no. 7, pp. 4242-4248, 2021.

[7] M.-L. Hu, M. Y. Masoomi, and A. Morsali, "Template strategies with MOFs," Coordination Chemistry Reviews, vol. 387, pp. 415-435, 2019.

[8] M.-L. Hu, V. Safarifard, E. Doustkhah et al., "Taking organic reactions over metal-organic frameworks as heterogeneous catalysis," Microporous and Mesoporous Materials, vol. 256, pp. 111-127, 2018.

[9] M. L. Hu, M. Abbasi-Azad, B. Habibi et al., "Electrochemical applications of ferrocene-based coordination polymers," ChemPlusChem, vol. 85, no. 11, pp. 2397-2418, 2020.

[10] L. Fan, D. Zhao, B. Li et al., "Luminescent binuclear Zinc(II) organic framework as bifunctional water-stable chemosensor for efficient detection of antibiotics and $\mathrm{Cr}(\mathrm{VI})$ anions in water," Spectrochimica Acta Part A: Molecular and Biomolecular Spectroscopy, vol. 264, Article ID 120232, 2002.

[11] L. Fan, D. Zhao, H. Zhang et al., "A hydrolytically stable amino-functionalized Zinc(II) metal-organic framework containing nanocages for selective gas adsorption and luminescent sensing," Microporous and Mesoporous Materials, vol. 326, Article ID 111396, 2021.

[12] H. Ran, H. Du, C. Ma, Y. Zhao, D. Feng, and H. Xu, "Effects of A/B-site Co-doping on microstructure and dielectric thermal stability of AgNbO3 ceramics," Science of Advanced Materials, vol. 13, no. 5, pp. 741-747, 2021.

[13] Y.-P. He, Y.-X. Tan, and J. Zhang, "Gas sorption, secondorder nonlinear optics, and luminescence properties of a series of lanthanide-organic frameworks based on nanosized tris((4-carboxyl) phenylduryl)amine ligand," Inorganic Chemistry, vol. 52, no. 21, pp. 12758-12762, 2013.

[14] B. Liu, W.-P. Wu, L. Hou, Z.-S. Li, and Y.-Y. Wang, "Two nanocage-based metal-organic frameworks with mixed- 
cluster SBUs and $\mathrm{CO} 2$ sorption selectivity," Inorganic Chemistry, vol. 54, no. 18, pp. 8937-8942, 2015.

[15] X. Zhang, Y.-Y. Huang, Q.-P. Lin, J. Zhang, and Y.-G. Yao, "Using alkaline-earth metal ions to tune structural variations of 1,3,5-benzenetricarboxylate coordination polymers," Dalton Transactions, vol. 42, no. 6, pp. 2294-2301, 2013.

[16] X. Zhang, Y.-Y. Huang, J.-K. Cheng, Y.-G. Yao, J. Zhang, and F. Wang, "Alkaline earth metal ion doped Zn(ii)-terephthalates," CrystEngComm, vol. 14, no. 14, pp. 4843-4849, 2012.

[17] Y.-H. Luo, A.-D. Xie, M.-G. Hu, J. Wu, D.-E. Zhang, and Y.-Q. Lan, "Assembly of two mesoporous anionic metal-organic frameworks for fluorescent sensing of metal ions and organic dyes separation," Inorganic Chemistry, vol. 60, no. 1, pp. 167-174, 2021.

[18] X. Zhou, X. Guo, L. Liu et al., "Two d10 luminescent metalorganic frameworks as dual functional luminescent sensors for $(\mathrm{Fe} 3+, \mathrm{Cu} 2+)$ and 2,4,6-trinitrophenol (TNP) with high selectivity and sensitivity," RSC Advances, vol. 10, no. 8, pp. 4817-4824, 2020.

[19] Y. Shen, X.-F. Yang, H.-B. Zhu, Y. Zhao, and W.-S. Li, "A unique 3D metal-organic framework based on a 12-connected pentanuclear Cd(ii) cluster exhibiting proton conduction," Dalton Transactions, vol. 44, no. 33, pp. 14741-14746, 2015.

[20] G. M. Sheldrick, "Crystal structure refinement withSHELXL," Acta Crystallographica Section C Structural Chemistry, vol. 71, no. 1, pp. 3-8, 2015.

[21] P. van der Sluis and A. L. Spek, "BYPASS: an effective method for the refinement of crystal structures containing disordered solvent regions," Acta Crystallographica Section A Foundations of Crystallography, vol. 46, no. 3, pp. 194-201, 1990.

[22] S. E. H. Etaiw, T. A. Fayed, M. M. El-bendary, and H. Marie, "Three-dimensional coordination polymers based on trimethyltin cation with nicotinic and isonicotinic acids as anticancer agents," Applied Organometallic Chemistry, vol. 32, Article ID 2100033, 2018.

[23] K. Wang, X. Ma, D. Shao, Z. Geng, Z. Zhang, and Z. Wang, "Coordination-induced assembly of coordination polymer submicrospheres: promising antibacterial and in vitro anticancer activities," Crystal Growth \& Design, vol. 12, no. 7, pp. 3786-3791, 2012.

[24] Z. Hu, M. Zhao, J. Su et al., "Three coordination polymers based on a star-like geometry 4, 4, 4" -nitrilotribenzoic acid ligand and their framework dependent luminescent properties," Journal of Solid State Chemistry, vol. 258, pp. 328-334, 2018.

[25] L. Liu, J. Ding, C. Huang, M. Li, H. Hou, and Y. Fan, "Polynuclear CdII polymers: crystal structures, topologies, and the photodegradation for organic dye contaminants," Crystal Growth \& Design, vol. 14, no. 6, pp. 3035-3043, 2014.

[26] L.-T. Cui, Y.-F. Niu, J. Han, and X.-L. Zhao, "Ancillary ligandassisted assembly of C3-symmetric $4,4^{\prime}, 4^{\prime \prime}$-nitrilotribenzoic acid with divalent $\mathrm{Zn} 2+$ ions: syntheses, topological structures, and photoluminescence properties," Journal of Solid State Chemistry, vol. 227, pp. 155-164, 2015.

[27] L. Fan, D. Zhao, B. Li et al., "An exceptionally stable luminescent cadmium(ii) metal-organic framework as a dual-functional chemosensor for detecting $\mathrm{Cr}(\mathrm{vi})$ anions and nitro-containing antibiotics in aqueous media," CrystEngComm, vol. 23, no. 5, pp. 1218-1225, 2021. 